\title{
Construcción de pantallas y anclajes en el solar del Mercado de la Encarnación en Sevilla: modelo de cálculo, estudio de desplazamientos y propuesta de intervención
}

\section{Construction of diaphragm walls and anchors under the Market of the Encarnacion in Seville: calculation model, movement study and intervention propose}

F. J. Bernal-Serrano $^{(*)}$, A. Jaramillo-Morilla ${ }^{(*)}$, R. D. Cano-Marín ${ }^{(*)}$, D. Moreno-Rangel ${ }^{(*)}$

\section{RESUMEN}

La construcción de las pantallas en el solar de la plaza de la Encarnación, surge tras la demolición en 1972 del Antiguo Mercado de Abastos. Esta actuación estaba englobada dentro de la concesión administrativa que el Ayuntamiento de Sevilla adjudicó para la construcción de un nuevo Mercado y Aparcamiento Subterráneo. Como anejo del proyecto, se calcularon las pantallas que albergarían 3 niveles bajo rasante, con los condicionantes de minimizar la afección a los edificios y viales circundantes. Las pantallas se realizaron entre Julio y Noviembre de 2002. Se construyeron un total de $8.835 \mathrm{~m}^{2}$ y $1.840 \mathrm{~m}^{2}$ de pantalla de espesor 80 y $100 \mathrm{~cm}$ respectivamente. Con la estructura de contención ejecutada, comienzan a realizarse los anclajes provisionales entre mayo y septiembre de 2003. La investigación expone el método de cálculo utilizado para las pantallas y anclajes, los gráficos de deformación y la comprobación con lo realmente medido con los inclinómetros.

Palabras clave: Método de cálculo; pantallas hormigón armado; inclinómetros; anclajes al terreno.

\section{ABSTRACT}

The construction of reinforced concrete diaphragm walls under Encarnación Square comes after the demolition in 1972 of the antique "Mercado de Abastos". Those works were included into the administrative concession of the Sevilla City Council for the constructions of a new market and underground parking. As the project annex, were made the calculation of the building's diaphragm walls would contain 3 levels underground, with the conditioning factors to avoid damages on the buildings and roads around. The wall's execution started on July and finished on November 2002. A total of $8835 \mathrm{~m}^{2}$ and $1840 \mathrm{~m}^{2}$ were built with $80 \mathrm{~cm}$ and $100 \mathrm{~cm}$ of thickness respectively. Once the containment structure was finished, the anchorages works begin between May and September 2003. This investigation exposes the calculation method used for the walls and anchors and shows the graphic of deformation obtained by inclinometers.

Keywords: Calculation method; diaphragm walls; inclinometers; anchors.

(*) Escuela Técnica Superior de Arquitectura - Universidad de Sevilla (España).

Persona de contacto/Corresponding author: fberser@ciccp.es (F.J. Bernal-Serrano)

Cómo citar este artículo/Citation: Bernal-Serrano, F. J., Jaramillo-Morilla, A., Cano-Marín, R.D., Moreno-Rangel, D. (2015).

Construcción de pantallas y anclajes en el solar del Mercado de la Encarnación en Sevilla: modelo de cálculo, estudio de desplazamientos y propuesta de intervención. Informes de la Construcción, 67(537): e051, doi: http://dx.doi.org/10.3989/ic.12.116.

Licencia / License: Salvo indicación contraria, todos los contenidos de la edición electrónica de Informes de la Construcción se distribuyen bajo una licencia de uso y distribución Creative Commons Reconocimiento no Comercial 3.o. España (cc-by-nc). 


\section{OBJETIVO DEL ESTUDIO}

El presente artículo tiene el objetivo de analizar el comportamiento real de las pantallas ejecutadas con el resultado obtenido en el modelo de cálculo utilizado para el dimensionamiento de las mismas. De igual manera, se expondrán distintas propuestas de intervención ante patologías detectadas como resultado de deficiencias en la ejecución del sistema de cimentación mediante pantallas en el edificio objeto del presente estudio.

Tras adjudicar el Ayuntamiento de Sevilla la concesión administrativa de proyecto, obra y explotación del Mercado, Galería Comercial y Aparcamientos Subterráneos, se inicia la redacción del proyecto constructivo con su correspondiente cálculo de las pantallas del edificio que albergará 3 niveles bajo rasante, con los condicionantes de minimizar la afección a los edificios y viales circundantes a la plaza de la Encarnación, ubicación descrita en la Figura 1.

Para evitar los daños a las construcciones vecinas es necesario:

- Garantizar la estanqueidad del recinto durante la excavación y la vida útil.

- Limitar los movimientos, principalmente horizontales en los edificios vecinos.

Por estas razones se eligió una solución de pantallas de hormigón armado realizadas in situ, empotradas en las margas.

La presencia de excavaciones arqueológicas en la parcela imposibilitaba la ejecución del edificio del Mercado de la Encarnación por el sistema ascendente-descendente, ya que no podían ejecutarse los forjados de la obra, al carecer de una superficie libre en la parcela. Este sistema ascendente-des-

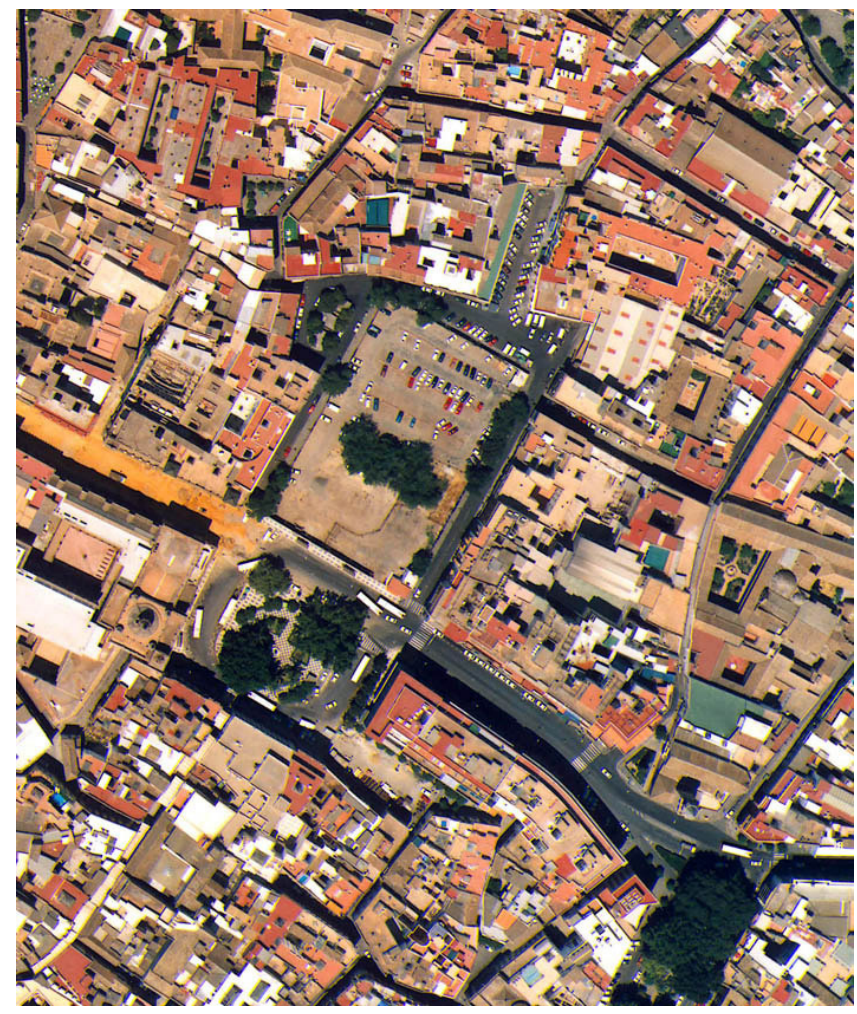

Figura 1. Estado anterior a la intervención.

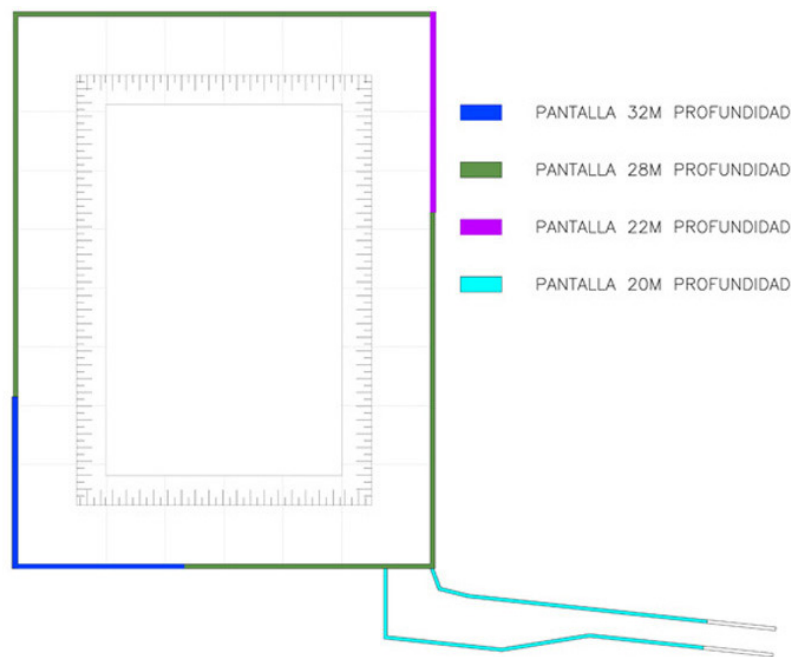

Figura 2. Profundidad de pantallas.

cendente haría que los desplazamientos de la pantalla y los esfuerzos fuesen mínimos.

Tampoco fue posible la realización de las pantallas y la excavación completa, dejándolas en voladizo, por lo que se utilizó sistemas de arriostramientos provisionales.

Se optó por anclar las pantallas al terreno mediante cables pretensados situados en un nivel, la utilización de la losa de cimentación del fondo como segundo apoyo, realizándose la construcción de la losa junto a las pantallas mediante bataches, realizando primero la parte central, y por bataches de aproximación a las pantallas, dejando bermas de tierra, con una altura aproximada de 5 metros.

Las pantallas se excavaron utilizando para el sostenimiento lodos tixotrópicos. Para minimizar el caudal de filtración por las juntas entre bataches se proyectaron bataches de 5 metros de longitud. En cuanto a la profundidad de las pantallas, aunque por razones de estabilidad no era necesario, se proyectaron las pantallas con tres profundidades $(22,28$ y $32 \mathrm{~m}$, tal y como se indica en la Figura 2), dependiendo de la capa de marga azul reconocida en los sondeos, de manera que se garantizase la penetración en las margas (al menos 2,50 metros, tal y como se indica en la Figura 3) de forma que el recinto creado fuese prácticamente impermeable.

Como dato significativo del estudio, hay que indicar que lo inicialmente proyectado no llegó a construirse completamente, debido a la presencia de restos arqueológicos en la parcela que hicieron modificar el proyecto de la concesionaria con 3 niveles de sótano a un nuevo proyecto de mercado sin aparcamiento subterráneo y con una sola planta bajo rasante que contenía el museo con los restos arqueológicos hallados. Por tanto, el estudio se limita a los 5-6 m excavados.

\section{ANTECEDENTES}

La información recopilada para la confección de este artículo proviene en su mayor parte del Proyecto de Construcción realizado por la concesionaria y los estudios previos realizados por el laboratorio de control de calidad Vorsevi. También se recaba información facilitada por el Departamento de Ingeniería del terreno de la Universidad de Sevilla durante el 


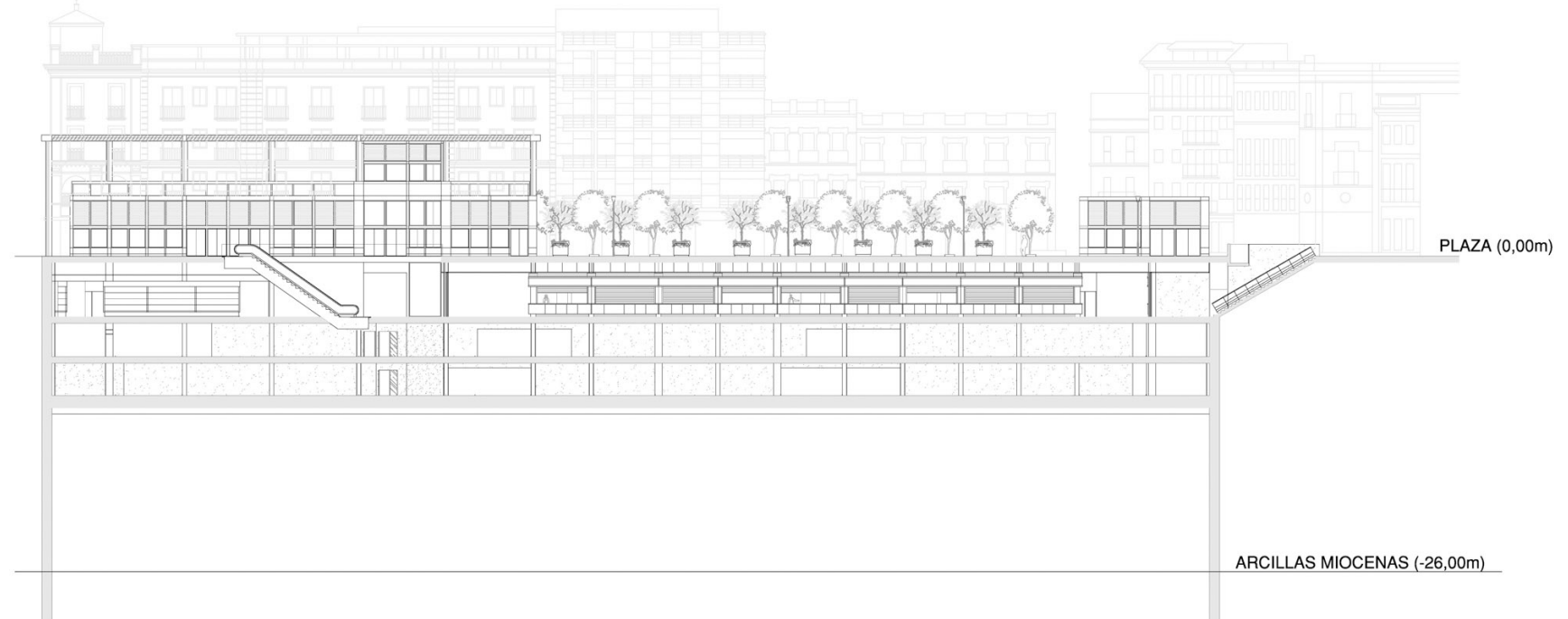

Figura 3. Propuesta de intervención.

seguimiento de las lecturas de los inclinómetros con material de laboratorio de la Escuela Superior de Arquitectura de Sevilla.

\section{METODOLOGÍA PARA EL CÁlCULO TEÓRICO DE PANTALLAS Y ANCLAJES AL TERRENO}

\subsection{Estudio Geotécnico}

Los parámetros geotécnicos utilizados para el dimensionamiento de las pantallas se obtuvieron de los estudios geotécnicos realizados por la empresa de control de calidad Vorsevi.

Se realizaron cinco sondeos a rotación, dos en una primera fase a petición de la Gerencia de Urbanismo del Ayuntamiento de Sevilla realizados para elaborar el anteproyecto, y tres en Febrero de 2002 realizados por la empresa concesionaria. El estudio geotécnico realizado en el solar era adecuado (5 para un solar de más de $6500 \mathrm{~m}^{2}$ ) teniendo en cuenta los condicionantes fijados por el CTE BD-SE Cimientos (1), en cuanto a número de sondeos, considerando un tipo de edificación C-1 y un grupo de terreno T-2. Según la tabla 3.4 CTE BD-SE Cimientos el $n^{0}$ mínimo de puntos de reconocimiento sería de 3 unidades, siendo 2 de ellos sondeos.

Con estos datos se realizó un perfil geotécnico tipo, grafiado en la Figura 4, con el que se realizaron los cálculos.

En el proceso de cálculo y posterior construcción de las pantallas y anclajes, se fijaron las siguientes variables:

- Situaciones de cálculo.

- Método de cálculo.

- Análisis de esfuerzos y deformaciones.

- Análisis de anclajes al terreno.

\subsection{Situaciones de cálculo}

Las pantallas continuas de hormigón se ven sometidas durante la construcción a situaciones de carga que pueden ser mayores a las finales de servicio. Por esta razón, resulta imprescindible analizar las sucesivas situaciones de carga a la que se ve sometida la pantalla durante la construcción, tal y como indica la bibliografía especifica en cálculo de cimentaciones (2) y (3).

Situación provisional (P). Se estableció el siguiente proceso constructivo:

Fase o: Ejecución de la pantalla desde la cota del terreno.

Fase 1: Excavación del recinto interior en una profundidad de 3 metros (para que las deformaciones de la pantalla sean reducidas), tal y como indica la Figura 5.

Fase 2: Ejecución de excavaciones para realización de anclajes hasta la cota $-4,50 \mathrm{~m}$. Ejecución de fila de anclajes a la cota $-4,00 \mathrm{~m}$, se colocan 3 anclajes por módulo de pantalla

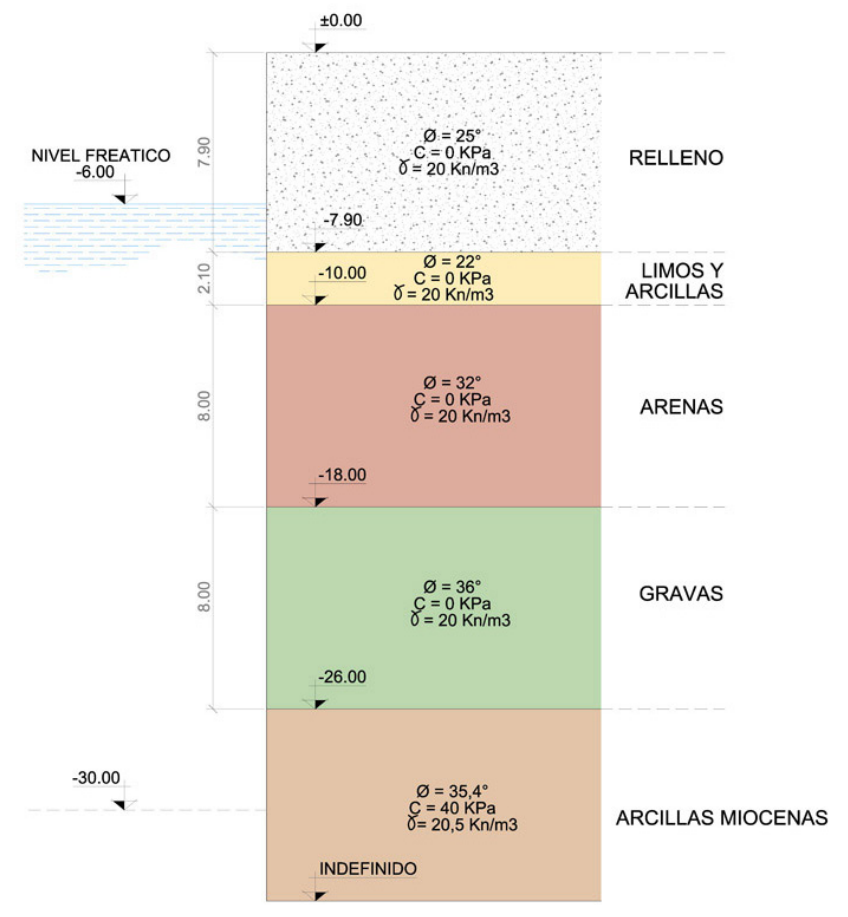

Figura 4. Perfil geotécnico de cálculo. 


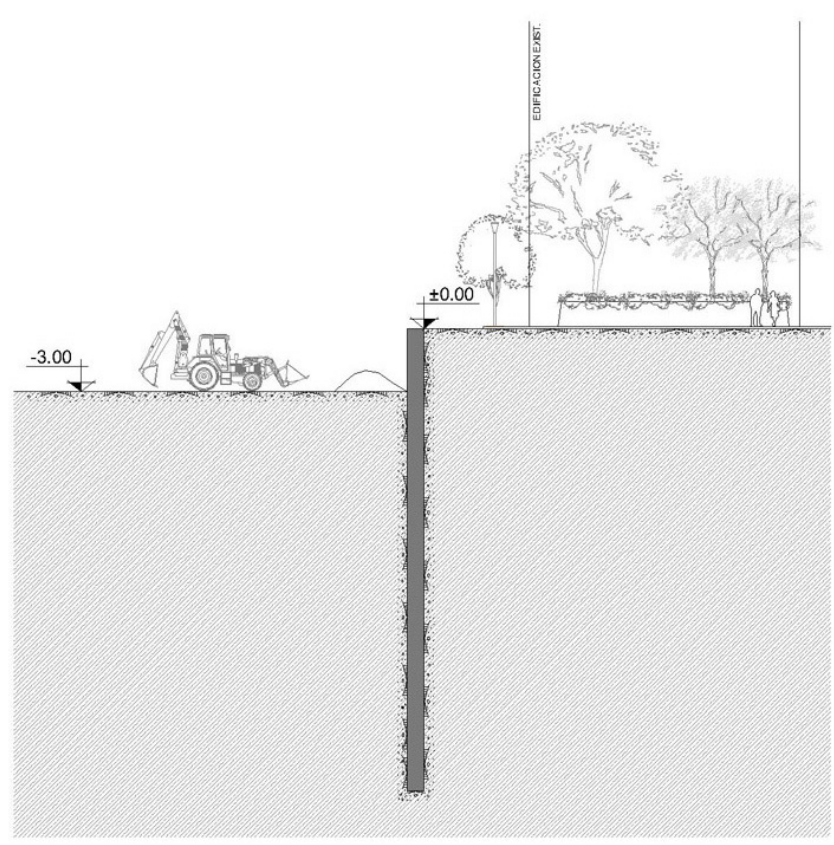

Figura 5. Fase $1^{\mathrm{a}}$ construcción.

de 5 metros, tal y como indica la Figura 6. El anclaje central con $45^{\circ}$ y los laterales con $30^{\circ}$. Estos anclajes serán dimensionados para $1500 \mathrm{Kn}$.

Fase 3: Excavación completa del recinto hasta la cota $-8,00 \mathrm{~m}$, tal y como indica la Figura 7 . Esta fase coincidió con el final de la intervención al hallarse restos arqueológicos de valor que hicieron tomar la decisión municipal de diseñar un nuevo edificio sin excavar por debajo de la cota donde aparecieron restos de antiguas civilizaciones.

Fase 4: Excavación en la parte central del recinto hasta la cota $-13,60 \mathrm{~m}$. Esta excavación sería en una anchura aproximada de 15 metros. Se deja en bermas el resto del terreno (10 metros al lado de cada pantalla y $45^{\circ}$ de inclinación).

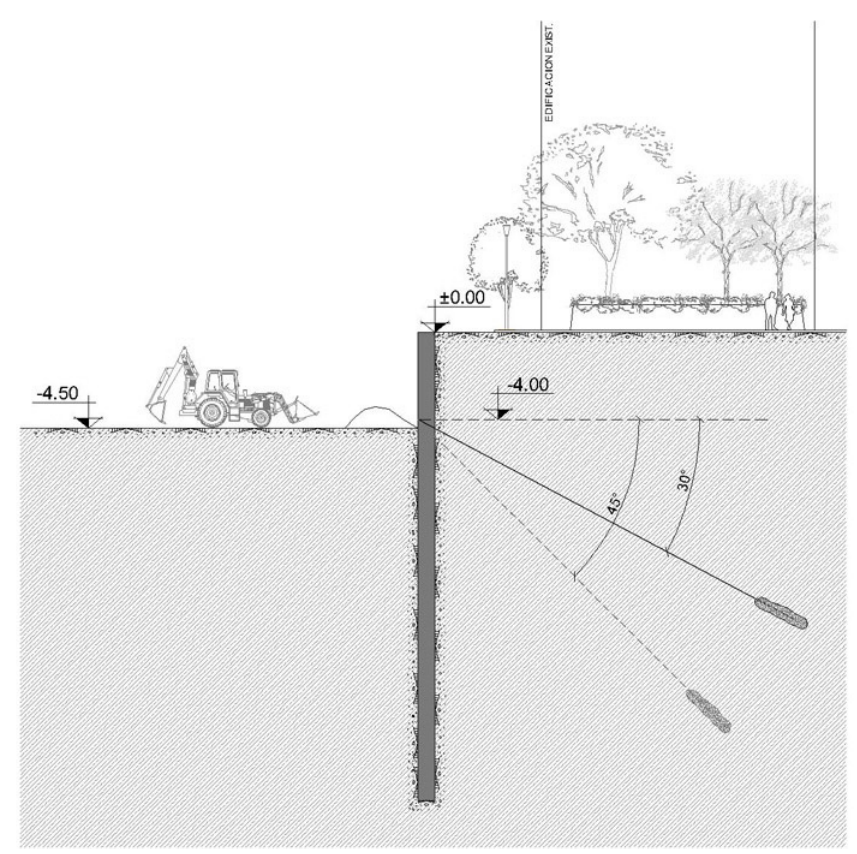

Figura 6. Fase $2^{\mathrm{a}}$ construcción.

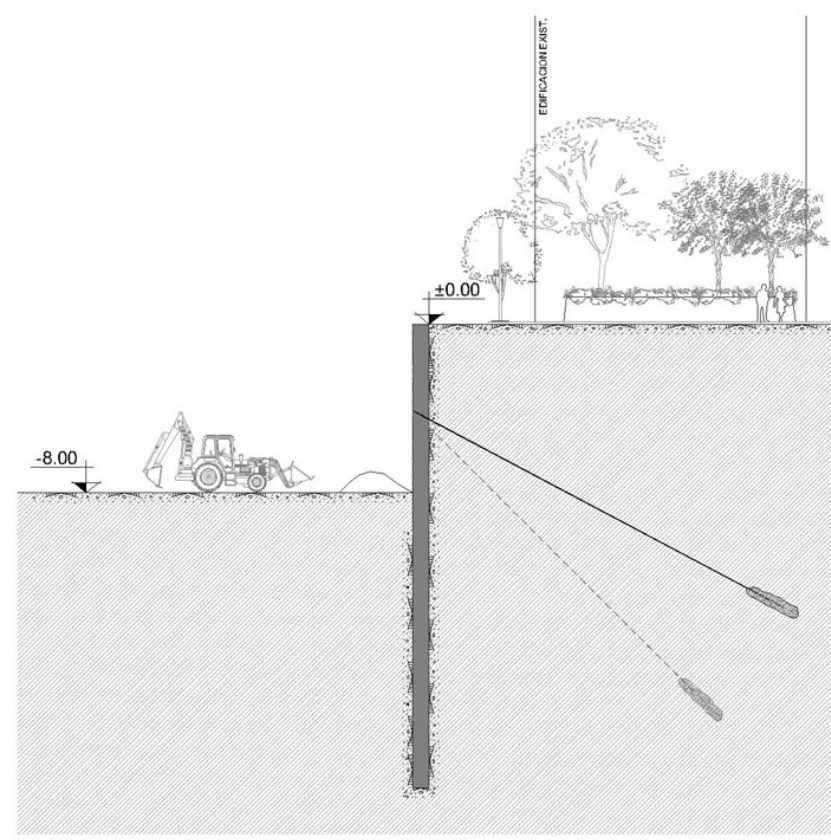

Figura 7. Fase $3^{\mathrm{a}}$ construcción y última.

Fase 5: Ejecución de la losa en parte central a la cota $-13,60 \mathrm{~m}$. Realización de la losa hasta las pantallas mediante bataches alternos excavados de anchura aproximada 15 metros.

Fase 6: Ejecución de la estructura, apoyando la pantalla en los sucesivos forjados y a nivel de cimentación.

\section{Situación Final (F).}

Las pantallas ancladas hiperestáticamente con varias filas de puntales y empotramiento sobredimensinado, presenta en la mayor parte de los casos zonas plásticas y elásticas; por lo tanto los cálculos exactos no son fáciles. Se realizaron los cálculos considerando la pantalla apoyada en los distintos forjados.

\subsection{Método de cálculo}

Se realizó el cálculo de pantallas mediante programa de ordenador utilizando el método de elementos finitos, basado en la modelización del terreno como un sistema de resortes, con una ley presión-corrimiento elastoplástica, desarrollado por la Universidad de Sevilla (4).

Se determinan los esfuerzos (momentos, flectores y cortantes) de la pantalla, flechas, empujes del terreno en todos sus puntos y solicitaciones en los anclajes y puntales para las distintas fases de la excavación.

El método admite para un terreno cohesivo cálculos a corto, medio y largo plazo. Puede considerarse cualquier ley de presiones del agua, así como sobrecargas y acciones exteriores.

- Datos de partida.

- Definición geométrica de la pantalla y de los anclajes, así como el número de fases de la excavación.

- Definición mecánica de la pantalla y de las diferentes capas del terreno.

- Definición del número de particiones en que queremos discretizar la pantalla. 
- Definición de sobrecargas y niveles freáticos en el intradós y trasdós así como las cargas exteriores actuantes, incluidas las de pretensado de anclajes en las sucesivas fases.

- Resultados obtenidos.

Para cada fase de excavación se obtiene:

- Ley de empujes sobre la pantalla.

- Deformada de la pantalla.

- Momentos y cortantes en la pantalla.

- Tracción en los anclajes.

Todos los parámetros se refieren a una longitud unidad de pantalla, ya que se considera un estado de deformación plana.

- Descripción del modelo.

- El terreno se comporta como una serie de muelles de comportamiento no lineal y elástico. Se discretiza la pantalla en elementos finitos. En cada nodo las incógnitas son el desplazamiento horizontal (flecha) y el giro.

- Simulación de la excavación. En el estado inicial, cuando se ha iniciado la excavación, la pantalla está en equilibrio porque a cada lado de la misma los empujes del terreno (muelles) son iguales y opuestos. Al excavar desaparecerían los muelles que representan el terreno excavado.

- Tratamiento de la no-linealidad del sistema de ecuaciones. La resolución se realiza mediante un sistema iterativo.

\subsection{Análisis de esfuerzos y deformaciones}

Se realizaron 3 modelos de cálculo, con los espesores indicados en la Figura 8:

- Modelo 1. Pantallas de $60 \mathrm{~cm}$. Zona rampas de acceso.

- Modelo 2. Pantalla $80 \mathrm{~cm}$. Zona excavación de 3 sótanos.

- Modelo 3. Pantalla $100 \mathrm{~cm}$. Zona excavación de 3 sótanos con rampas interiores.

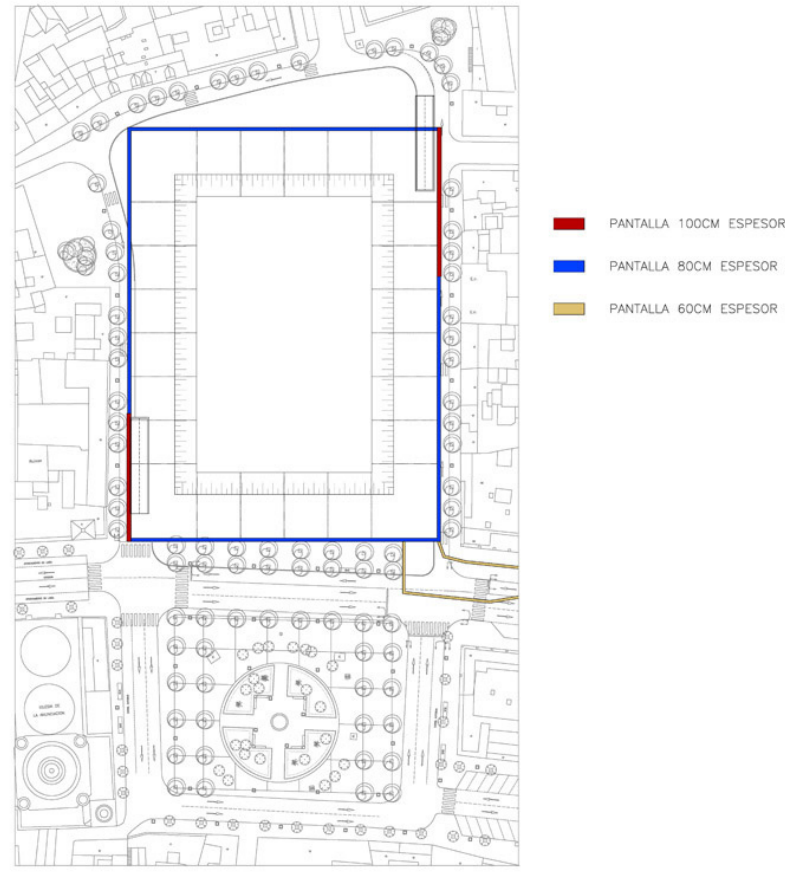

Figura 8. Espesores de pantallas.
El hecho que llevó a proyectar las pantallas de espesores de $100 \mathrm{~cm}$, fue la presencia cercana al sótano de los edificios de mayor valor histórico y antigüedad de la plaza, así como la presencia de las rampas internas del aparcamiento que carecían del suficiente arriostramiento causado por el resto de los forjados de sótano.

La envolvente de los esfuerzos para cada una de las fases, arrojó los siguientes resultados (Tabla 1), de forma gráfica en las Figuras 9 y 10.

Tabla 1. Envolvente de los esfuerzos.

\begin{tabular}{|c|c|}
\hline PANTALLA 80 CM & PANTALLA 1Oo CM \\
\hline $\mathrm{M}=594 \mathrm{mKn}$ & $\mathrm{M}=706 \mathrm{mKn}$ \\
\hline $\mathrm{M}=732 \mathrm{mKn}$ & $\mathrm{M}=864 \mathrm{mKn}$ \\
\hline $\mathrm{Q}=319 \mathrm{Kn}$ & $\mathrm{Q}=322 \mathrm{Kn}$ \\
\hline
\end{tabular}
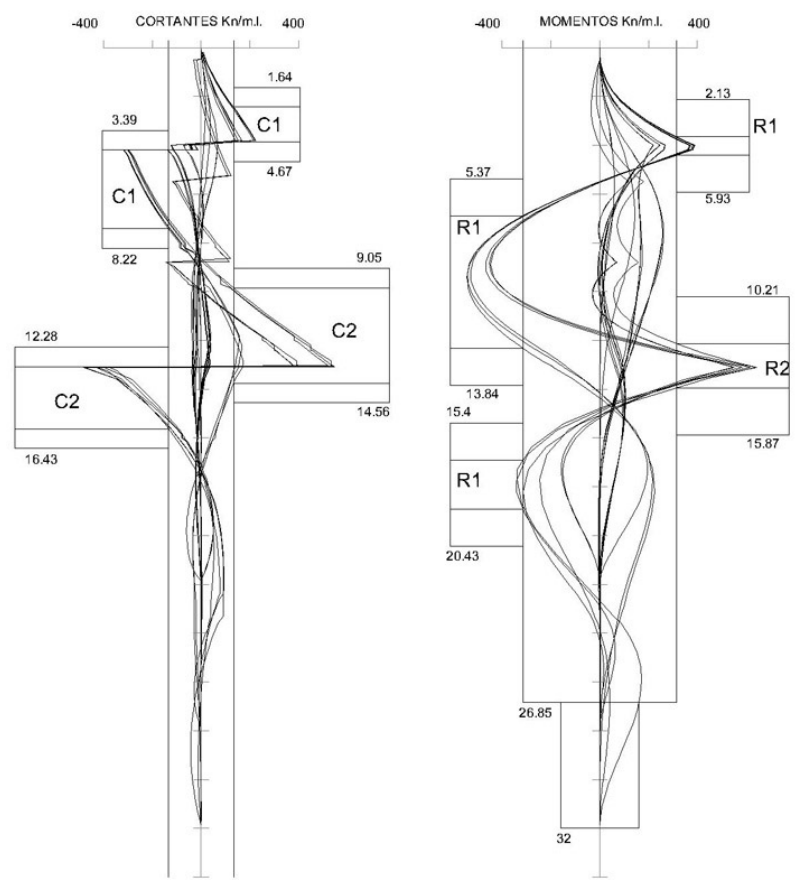

Figura 9. Envolvente esfuerzos pantalla $80 \mathrm{~cm}$.
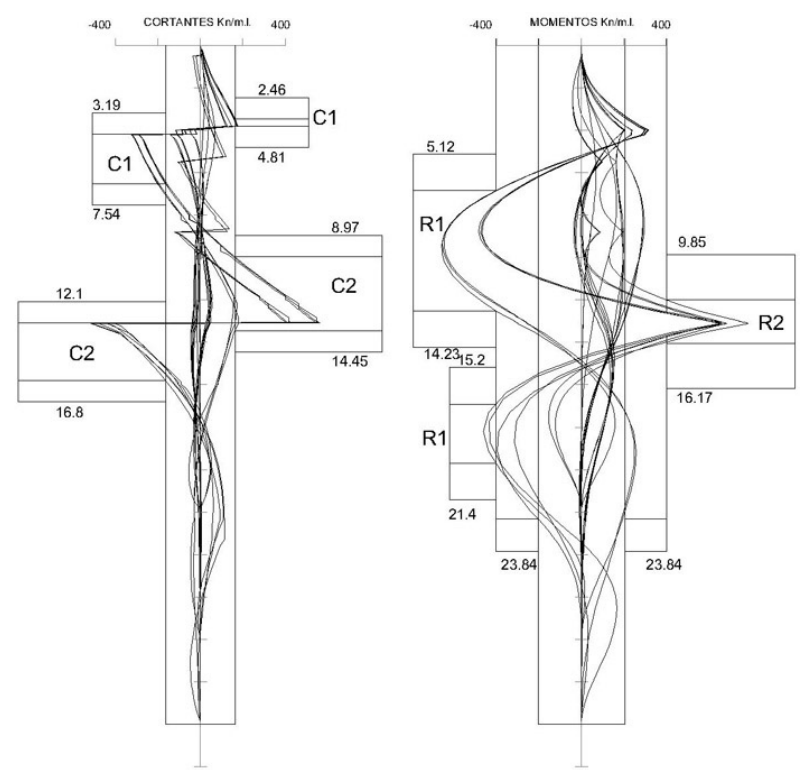

Figura 10. Envolvente esfuerzos pantalla $100 \mathrm{~cm}$. 
Se muestran a continuación la gráfica de la envolvente de esfuerzos:

El armado de la pantalla cubrió la envolvente de las armaduras obtenidas con un recubrimiento de los cercos de $7 \mathrm{~cm}$ como mínimo.

Respecto a la máxima deformación prevista en coronación de las pantallas durante el proceso constructivo, se obtuvieron por cálculo los siguientes resultados (Tabla 2), de forma gráfica en las Figura 11.

Tabla 2. Deformación pantallas.

\begin{tabular}{|c|c|}
\hline PANTALLA 80 CM & PANTALLA 100 CM \\
\hline $\mathrm{D}=19 \mathrm{~mm}$ & $\mathrm{D}=16 \mathrm{~mm}$ \\
\hline
\end{tabular}

Según el CTE BD-SE Cimientos, Estabilidad de las edificaciones próximas a pantallas, debe comprobarse para cada una de las fases de ejecución tanto de la pantalla en si como de la excavación, que los movimientos horizontales y verticales a que se vea sometido el terreno en el trasdós, sobre el que se encuentren cimentados los edificios medianeros o próximos, no son lo suficientemente importantes como para hacer peligrar la estabilidad de los mismos o ser causa de agrietamientos, inclinaciones, etc.

Pero no se aporta ningún dato cuantitativo sobre el orden de magnitud que pudiera producir daños a las edificaciones colindantes. Tampoco se aporta ningún dato sobre la relación existente entre asiento vertical y desplazamiento horizontal en función de la profundidad de excavación o distancia entre apoyos, del que sí obtenemos resultados de los estudios realizados por Oteo de la experiencia de la construcción del metro de Madrid durante los años 1999-2003 y que se relacionan en la siguiente Tabla 3 .

Tabla 3. Oteo 2003. Recomendaciones para estimar movimientos en pantalla.

\begin{tabular}{|l|c|c|}
\hline \multicolumn{1}{|c|}{ Tipo Terreno } & $\delta_{\text {hmáx }}$ & $\delta_{\text {vmáx }}$ \\
\hline Arcilla blanda & $2,5 \% \mathrm{H} \mathrm{a} 3,5 \% \mathrm{H}$ & $\sim 2 \% \mathrm{H}$ \\
\hline Arena floja y grava & $1,5 \% \mathrm{H} \mathrm{a} 2 \% \mathrm{H}$ & $\sim 0,5 \% \mathrm{H} \mathrm{a} 1 \% \mathrm{H}$ \\
\hline Arcilla rígida & $1 \% \mathrm{H} \mathrm{a} 1,5 \% \mathrm{H}$ & $0,1 \% \mathrm{H} \mathrm{a} 0,2 \% \mathrm{H}$ \\
\hline
\end{tabular}

En la tabla 2.3 del CTE DB SE-C se indican los valores límite basados en la distorsión horizontal de muros de carga (1/200o), que podrían usarse como referencia para establecer el máximo desplazamiento horizontal diferencial entre dos puntos conocida la distancia que los separa.

Según Justo y Manzanares, el umbral de desplazamientos de muros y pantallas que produce grietas es el de la Tabla 4 .

Al ser umbrales de daños, debemos de considerar un coeficiente de seguridad respecto a estos valores. El coeficiente de

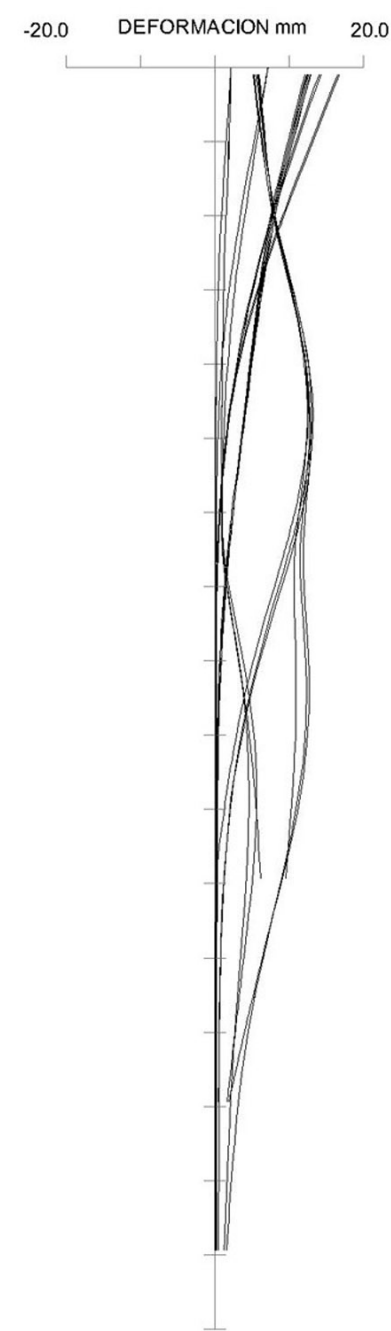

Deformada pantalla
$80 \mathrm{~cm}$

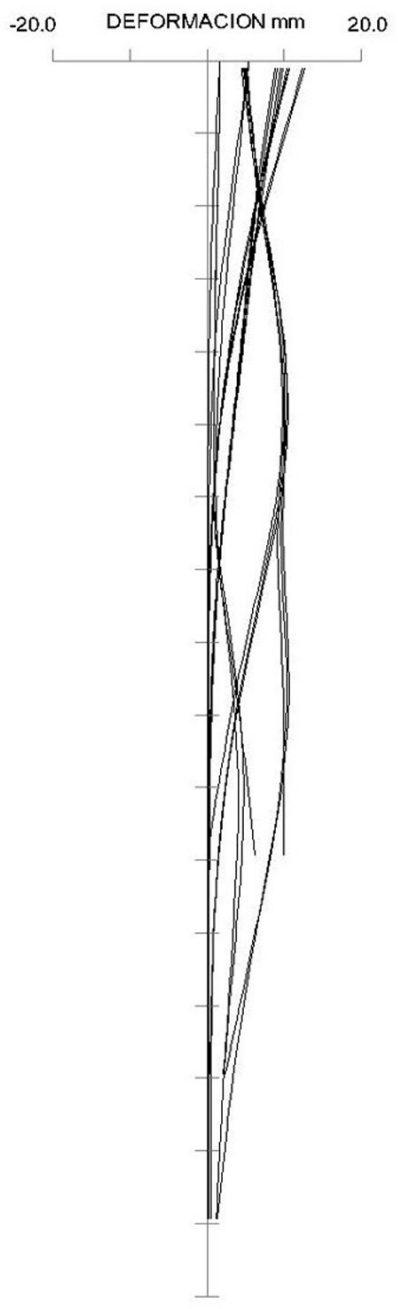

Deformada pantalla $100 \mathrm{~cm}$
Figura 11

seguridad normal suele oscilar de 1,25 a 1,5. Por esto, los valores máximos recomendados para no alcanzar los valores del umbral de daños serían de 16 y 50 mm en edificios antiguos y modernos respectivamente. Vamos a considerar para estas pantallas un desplazamiento lateral máximo y en superficie de $20 \mathrm{~mm}$ en la zona de la zona de las rampas, que coincide con la zona donde existen edificios antiguos. Es por la limitación de deformaciones, que en la zona de las rampas la pantalla es de $100 \mathrm{~cm}$ de espesor.

Según Clough (5), la máxima flecha horizontal no debe superar el $0,2 \% H$. Siendo la excavación de aproximadamente 13 metros, el máximo desplazamiento sería de $26 \mathrm{~mm}$. El valor

Tabla 4. Justo y Manzanares, 1989.

\begin{tabular}{|l|c|c|c|}
\hline \multicolumn{3}{|c|}{ UMBRAL DE DESPLAZAMIENTOS DE UN MURO PARA QUE SE PRODUZCA DAÑO } \\
EN EDIFICIOS VECINOS Y PAVIMENTOS PROXIMOS AL TRASDOS
\end{tabular}

* Daños severos en edificios con cimentación superficial. 
de 16 a 20 mm es más restrictivo, por lo que utilizamos este valor como máximo admisible.

\subsection{Análisis de anclajes al terreno}

Los anclajes necesarios para dotar de estabilidad a la pantalla durante la construcción se calcularon a la cota -4,00 m y en la Fase de excavación a $-8,00 \mathrm{~m}$, por tanto se cumplía lo fijado por el CTE DB SE-C respecto a no proyectar pantallas en voladizo en profundidades superiores a $5 \mathrm{~m}$; obteniéndose cargas horizontales de diseño de $600 \mathrm{Kn} / \mathrm{ml}$.

Se buscó anclar los tirantes en el estrato de arenas y gravas; para lo que es necesario realizar las perforaciones con una inclinación de $30^{\circ}$ y $45^{\circ}$ con la horizontal.

Dado que se proyectan bataches de 5 metros de longitud, se dimensionan tres anclajes por batache. La tracción por tirante para el cálculo sería de:

$$
\mathrm{T}=(600 \mathrm{Kn} / \mathrm{m} \cdot 5 \mathrm{~m}) / 3=1000 \mathrm{Kn}
$$

Se dimensionan anclajes formados por cordones de $\varnothing$ o,6" de acero Y186oS7 $\left(\mathrm{f}_{\max }=1860 \mathrm{~N} / \mathrm{mm}^{2}, \mathrm{f}_{\mathrm{yk}}=1767 \mathrm{~N} / \mathrm{mm}^{2}\right)$. Para la carga de servicio se limita la tensión a un $60 \%$ de la carga del límite elástico por lo que cada anclaje estará formado por 9 cordones de $\varnothing$ o,6” (139 mm² de sección nominal).

$$
\begin{gathered}
\mathrm{T}=9 \cdot 139 \mathrm{~mm}^{2} \cdot 0,6 \cdot 1767 \mathrm{~N} / \mathrm{mm}^{2}=1326310 \mathrm{~N}= \\
=1326,31 \mathrm{Kn}>1000 \mathrm{Kn}
\end{gathered}
$$

Se calculan los anclajes utilizando el método de Bustamante (6), considerando 5,7 metros en mezclas de arenas, arcillas y limos y diversas longitudes en las zahorras.

La longitud mínima necesaria de la cabeza de anclaje se calcula mediante un método aproximado empírico. Bajo el efecto de la fuerza de tracción a la que se somete el anclaje, tiende a arrastrar al terreno en su movimiento. La fuerza límite de extracción del anclaje es:

$$
\mathrm{P}_{\mathrm{nd}} /\left(\pi \mathrm{D}_{\mathrm{n}} \mathrm{L}_{\mathrm{b}}\right)<\mathrm{a}_{\mathrm{adm}}
$$

Siendo:

$\mathrm{P}_{\mathrm{nd}}=$ Carga nominal mayorada de cada anclaje.

$\mathrm{D}_{\mathrm{n}}=$ Diámetro nominal del bulbo)

$\mathrm{L}_{\mathrm{b}}=$ Longitud de cálculo del bulbo

$\mathrm{a}_{\mathrm{adm}}=$ Adherencia admisible frente arrancamiento del terreno que rodea al bulbo.

$$
\mathrm{a}_{\mathrm{adm}}=\mathrm{a}_{\lim } / \mathrm{F}_{3}
$$

Los valores de $\mathrm{a}_{\lim }$ se obtienen aplicando métodos empíricos, según la gráfica de adherencia límite en arcillas y limos de la Guía para el diseño y la ejecución de anclajes al terreno (7), con sistema de inyección IU.

Siendo $\mathrm{F}_{3}$ un coeficiente de valor 1,45 para anclajes provisionales.

La resistencia al deslizamiento del bulbo se puede calcular de igual modo por la expresión:

$$
\mathrm{a}_{\lim }=\mathrm{Kq}_{\mathrm{u}}
$$

siendo $\mathrm{K}$ un valor oscilante entre 5 y 2 decreciente en función del aumento de la resistencia a compresión simple.

En nuestro caso, para las mezclas de arena, limos y arcillas superficiales, consideramos $\mathrm{q}_{\mathrm{u}}$ con valores entre 66 a $12 \mathrm{KPa}$, tomando como valor medio $50 \mathrm{KPa}$, por tanto la resistencia media al deslizamiento del bulbo:

$$
\begin{aligned}
& \mathrm{a}_{\lim }=5 \cdot 50=250 \mathrm{KPa} \\
& \mathrm{a}_{\text {adm }}=25 \mathrm{O} / 1,45=172 \mathrm{KPa} \\
& \mathrm{L}_{\mathrm{b}} \geq 1000 \mathrm{Kn} \cdot 1,5 /(3,14 \cdot 0,15 \mathrm{~m} \cdot 172 \mathrm{KPa})=18 \mathrm{~m}
\end{aligned}
$$

Luego se fija una longitud de la cabeza de anclaje de 18 metros, con una longitud inicial atravesando relleno de 10 metros aproximadamente.

Para estos cálculos teóricos se realizaron las correspondientes pruebas en obra de arrancamiento del bulbo. Mediante gato de émbolo perforado y célula de carga se obtuvieron las cargas de arrancamiento del bulbo inyectado. Para los anclajes situados a $30^{\circ}$ con la horizontal, el arrancamiento del bulbo se producía a valores inferiores a los esperados, debido al hecho de que el bulbo se encontraba deficientemente anclado en la capa de gravas. Este motivo fue el que originó que la totalidad de los anclajes se proyectaran a $45^{\circ}$ con la horizontal, de manera que aseguraba que el bulbo penetraba en una mayor longitud en la capa de grava. Esta disposición más favorable para el correcto funcionamiento de los anclajes, originaba a la misma vez una menor afección a los edificios colindantes, ya que la profundidad del anclaje en la vertical del edificio presentaba mayor cota y por tanto mayor separación a las cimentaciones existentes.

\section{ANALISIS DE LA CAMPAÑA DE INCLINOMETRÍA}

La colocación de los inclinómetros se realizó durante la fase de hormigonado de las pantallas y la lectura inicial de los 8 inclinómetros se realizó el 10 de Febrero de 2003. Centraremos nuestro estudio en el I-4, el más próximo a las edificaciones relevantes. En la Figura 12 se grafía la disposición en planta de los tubos inclinométricos.

Se realizaron 4 mediciones en los siguientes intervalos de tiempo:

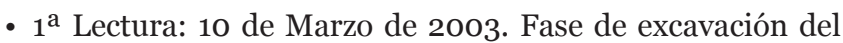
interior del recinto.

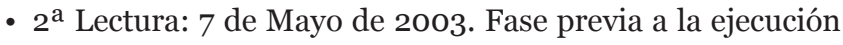
de los anclajes.

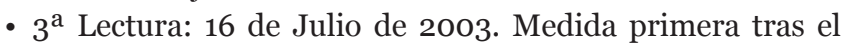
cambio de sonda o torpedo de $100 \mathrm{~cm}$ a $50 \mathrm{~cm}$ por el laboratorio de control de calidad del contratista.

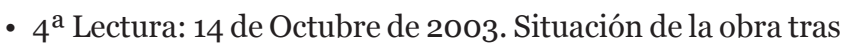
ejecución de los anclajes.

Las lecturas $\mathrm{n}^{0} 1 \mathrm{y} \mathrm{n}^{0} 2$ se realizaron con un espaciado de $1 \mathrm{~m}$ y las lecturas $\mathrm{n}^{0} 3 \mathrm{y} \mathrm{n}^{0} 4$ con un espaciado de $0,5 \mathrm{~m}$ para mayor precisión.

Según las deformaciones obtenidas en el cálculo, la desviación en el sentido perpendicular de la pantalla no debe superar los $20 \mathrm{~mm}$. 


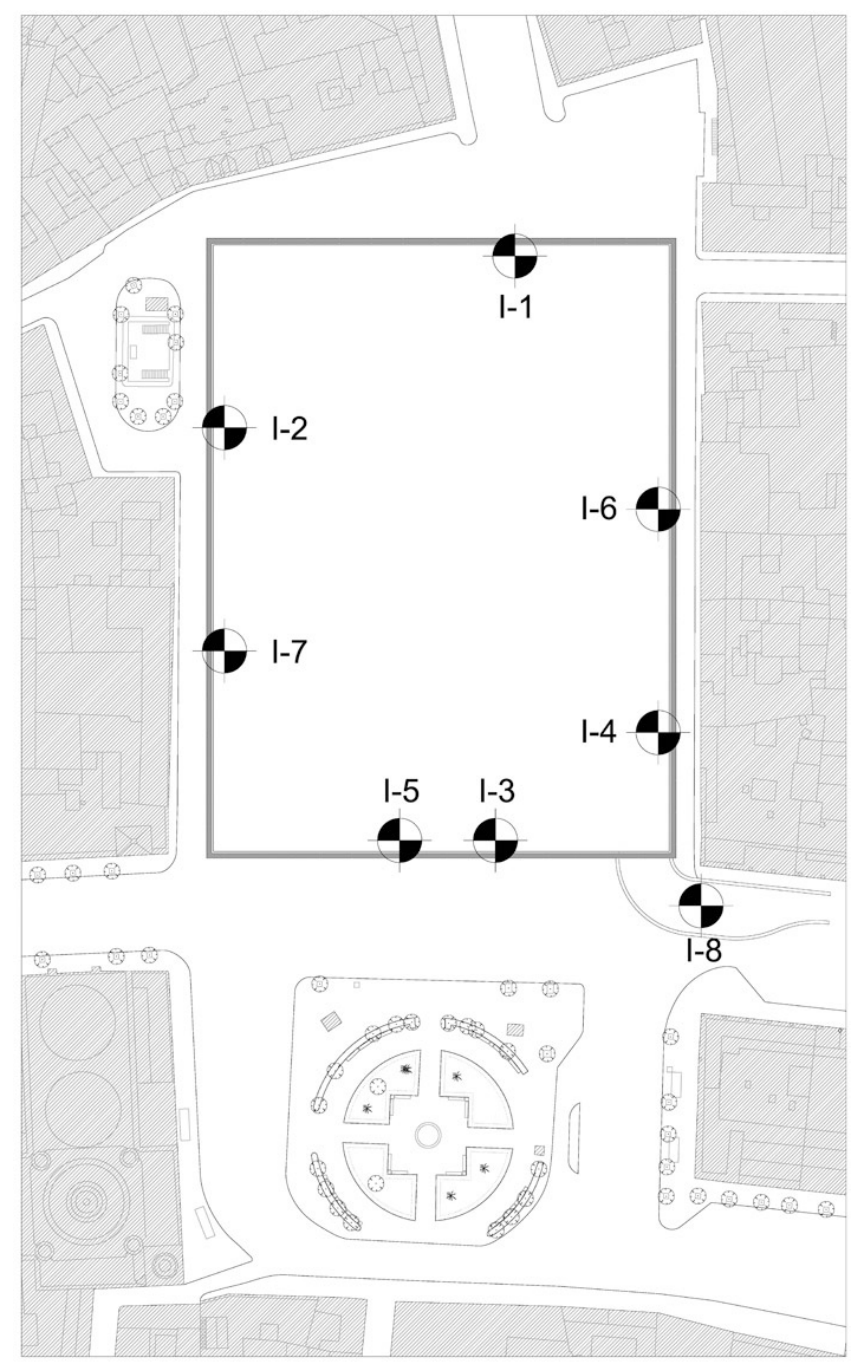

Figura 12. Planta general ubicación inclinómetros

En las cuatro lecturas tomadas durante el proceso de construcción se aprecian los movimientos ocurridos en la pantalla. Observamos como la variación más significativa sufrida por las mismas se produce en la fase de trabajo en ménsula, movimiento que está dentro de los márgenes admisibles para no afectar a la edificación cercana. Este hecho lo ratifica la no afección de la obra al viario perimetral. En la última lectura, tomada tras el proceso de anclado de las pantallas, se observa como la pantalla recupera su posición inicial contra el terreno, evitándose de este modo deformaciones en las cabezas de las mismas.

A continuación se reflejan los gráficos de los datos tomados por el laboratorio de control de calidad, VORSEVI (Figuras 13 y 14) y por el Laboratorio de la Escuela de Arquitectura de la Universidad de Sevilla (Figuras 15 y 16), tomadas sobre el mismo inclinómetro I-4, teniendo en cuenta los ejes del esquema siguiente.

Del análisis de las gráficas obtenidas, se puede concluir lo siguiente:

- Se obtienen valores similares una vez se acuerda un criterio uniforme para realización de lecturas (sonda o torpedo similar y forma de representación gráfica).

- Con la excavación que se realizó los movimientos en coronación de las pantallas estaban dentro de los límites admi-

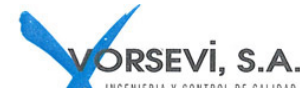

GRÁFICA DE DESVIACIÓN DEL EJE A.
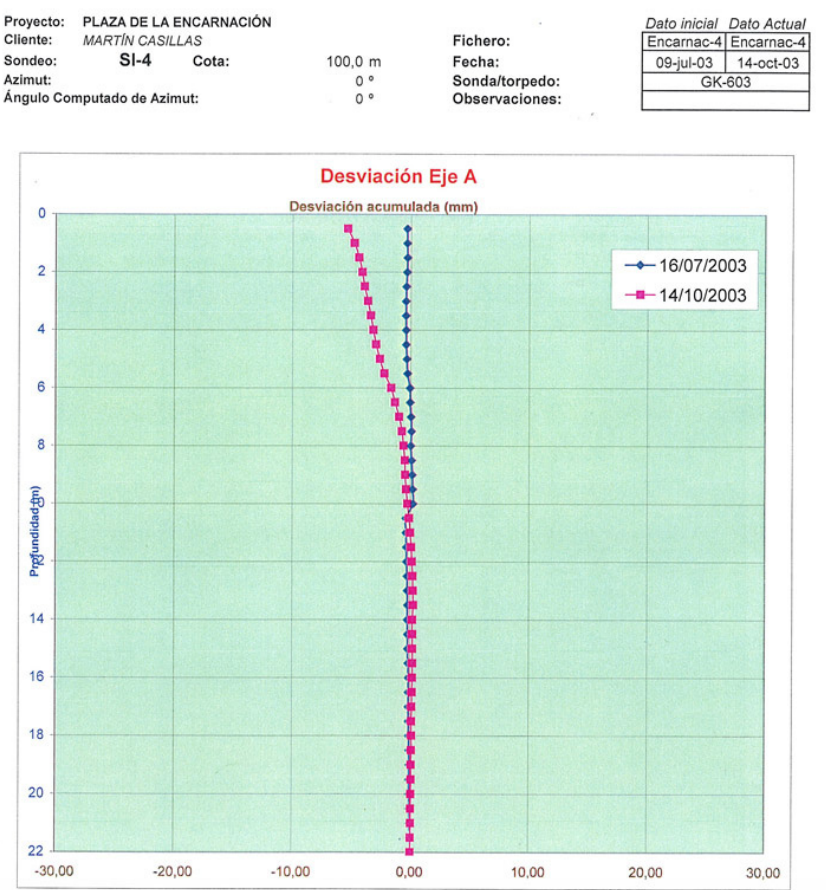

Figura 13. Lectura final eje A I-4.
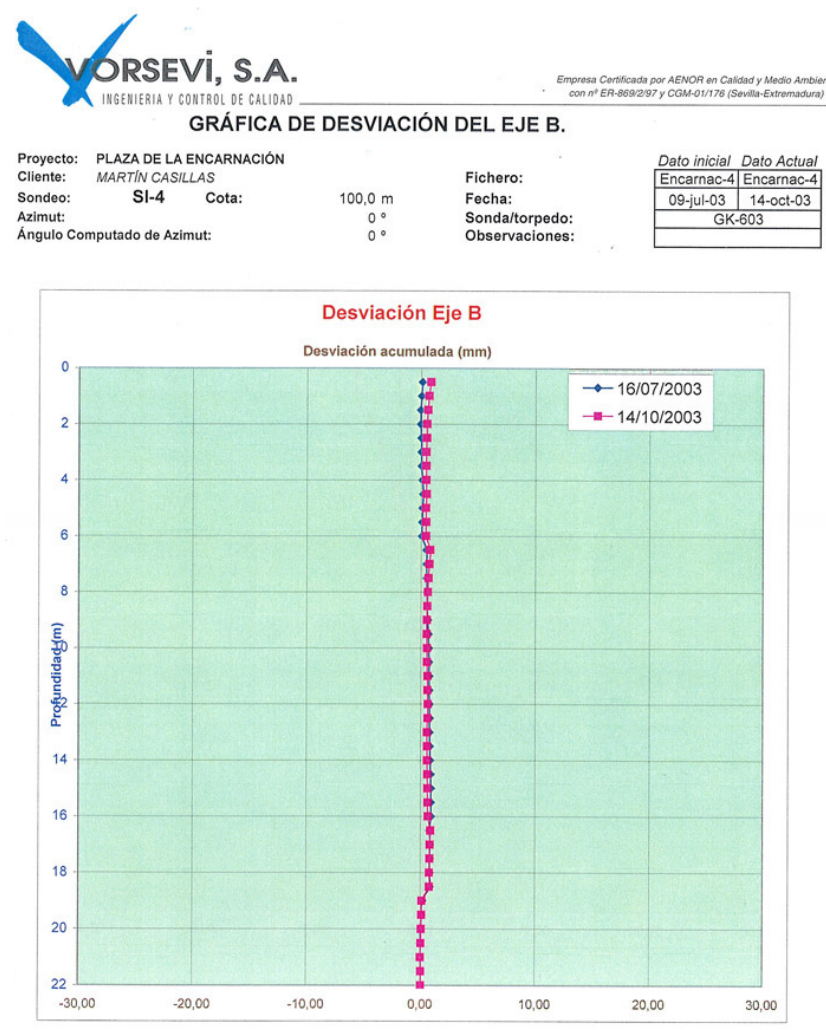

Figura 14. Lectura final eje B I-4.

sibles (inferior a $20 \mathrm{~mm}$ en la fase de ejecución en la que se paralizaron las obras).

- En la colocación de la tubería inclinométrica, el sellado entre tubos y manguitos, así como la cabeza de los remaches debe realizarse con cintas bituminosas. El sellado es mucho 


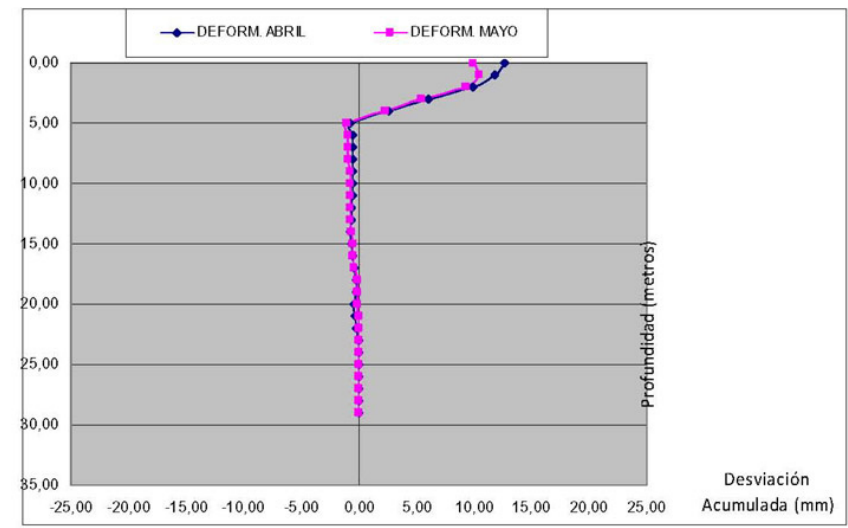

Figura 15. Lectura final eje A laboratorio Escuela Arquitectura I-4.

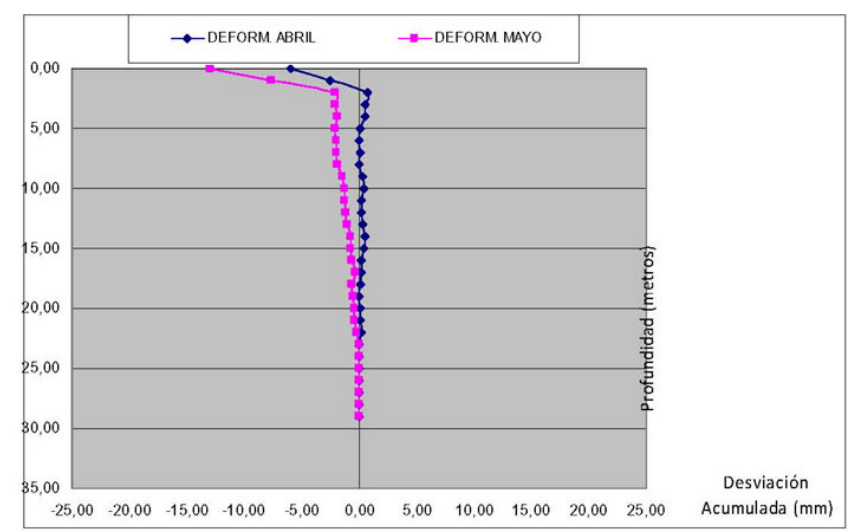

Figura 16. Lectura final eje B laboratorio Escuela Arquitectura I-4.

más efectivo y de esta manera en la zona de unión se consigue la impermeabilización. De realizarse de otra manera, se corre el riesgo de la introducción de alguna lechada en el tubo de aluminio, y la dificultad de introducir el torpedo en su interior, al quedar trozos endurecidos de lechada en las guías.

- De igual manera y para una correcta lectura, la cabeza de la tubería debe quedar protegida por una arqueta dotada de cerradura y llave. De permanecer abierta la parte superior del tubo, se corre el peligro de obstrucción de la tubería, ya que cualquier elemento introducido en la boca del tubo puede dar al traste con las mediciones, al impedir el descenso del torpedo.

- El tubo de PVC que protege durante el hormigonado a la tubería de aluminio del inclinómetro debe rellenarse convenientemente con mortero, de lo contrario pueden realizarse mediciones defectuosas a cotas profundas.

- En las lecturas tomadas en la obra por el laboratorio de control de calidad, se presentaron varias de las incidencias anteriormente descritas, por lo que la veracidad de los resultados podía ponerse en entredicho. Como dato reseñable, en el tubo inclinométrico I-4 lectura eje B (Figura 13), observamos como la gráfica refleja un movimiento próximo a los $15 \mathrm{~mm}$ en la coronación. Ello debido a que el tubo inclinométrico en su parte vista en superficie no estaba lo suficientemente anclado y permitía el desplazamiento, ya que la pantalla no experimentó ningún movimiento lateral. De igual forma, errores a la hora de representar gráficamente (Figura 17) y I-2 (Figura 18), se presentaba una discontinuidad a una profundidad desde la cota de rasante de unos -15 m y-20 m respectivamente. Estas desviaciones se podía estimar en unos $50 \mathrm{~mm}$ y $10 \mathrm{~mm}$ respectivamente. Este fenómeno, debería comprobarse con la posterior excavación de
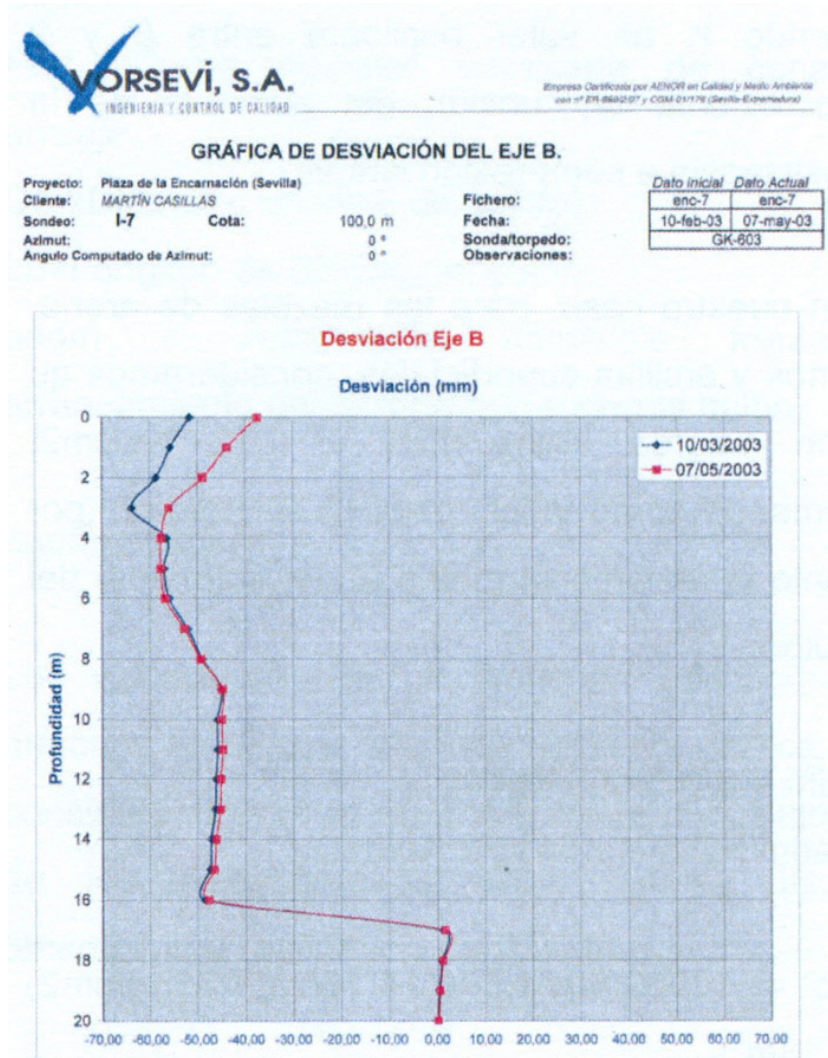

Figura 17. Lectura eje B I-7.
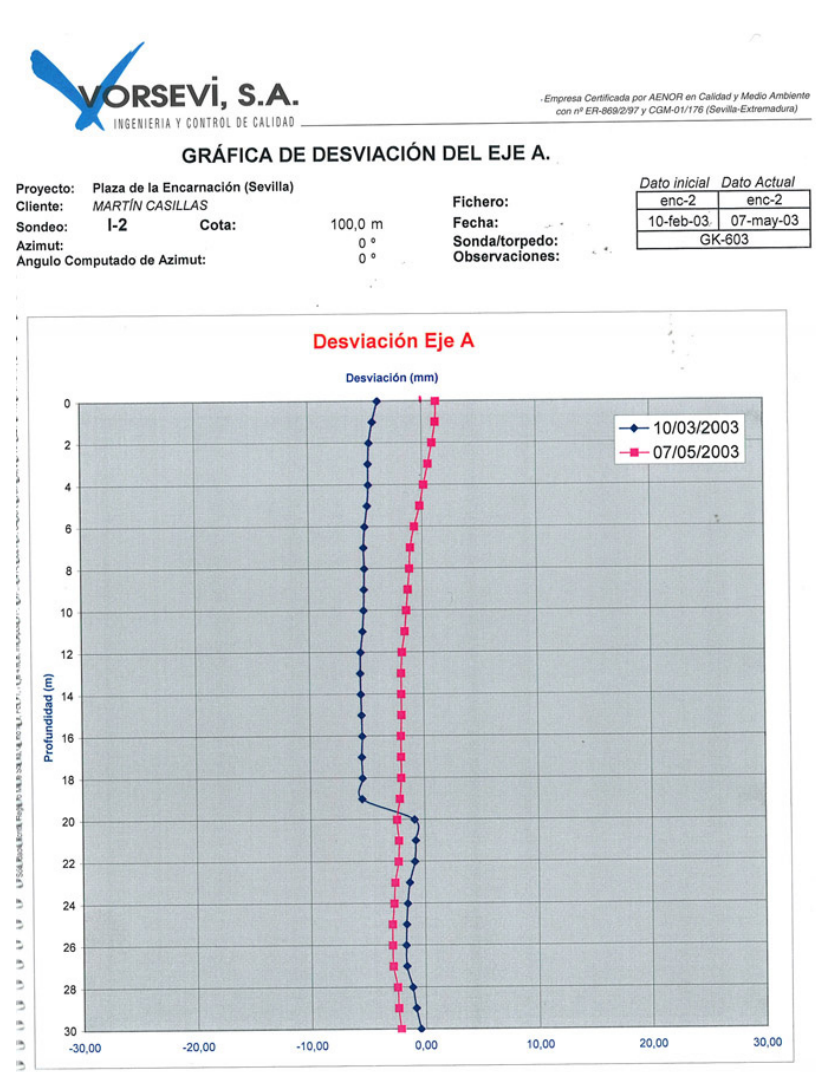

Figura 18. Lectura eje A I-2.

las pantallas. Es evidente que de ser ciertos estas mediciones, se habría producido un desplazamiento en ambos ejes de las pantallas, que podían haber ocasionado graves consecuencias de haberse producido la excavación completa. 


\section{RESULTADOS}

El análisis de la cimentación y anclajes que nos ocupa en el presente estudio, no llegó a construirse en su totalidad, debido a que el Ayuntamiento de Sevilla decidió paralizar las obras debido a la importancia de los hallazgos arqueológicos existentes en el solar. Por tanto, con la estructura de contención ejecutada y los anclajes provisionales, se realizaron los trabajos de excavación del interior del solar. Posteriormente se construyó el actual museo arqueológico Antiquarium, inaugurado el 27 de marzo de 2011 utilizando la estructura de contención del anterior proyecto.

El hecho de no excavar hasta la cota prevista en el proyecto de 3 plantas de sótano (cota -14 m aproximadamente), y sólo ejecutar la excavación hasta la cota arqueológica (cota $-6 \mathrm{~m}$ aproximadamente), dejó la incógnita del comportamiento estanco de los módulos de pantalla de $5 \mathrm{~m}$ de anchura entre sí.

Para el diseño inicial de la edificación se eligieron pantallas continuas de hormigón armado de espesores comprendidos entre 60 a $100 \mathrm{~cm}$ y juntas circulares. La experiencia en obras similares en la ciudad de Sevilla, indica que el tecleo de las pantallas observadas en las lecturas de los inclinómetros, hubiese producido problemas de filtración de agua procedente del nivel freático hacia el interior de la excavación, con el consiguiente arrastre de finos y problemas de asentamientos en edificaciones colindantes. La falta de verticalidad de las pantallas detectada en varios inclinómetros obligaba a recomendar medidas preventivas suplementarias: lecturas de niveles piezométricos en el exterior e interior del recinto de forma periódica, y especialmente, en las épocas de extracción de agua, para vigilar e impedir el arrastre de finos de los edificios medianeros, así como la creación de una corriente de agua del exterior al interior del recinto a través de las juntas.

La idea del comportamiento de las pantallas en profundidad y la adopción de las medidas correctoras necesarias deben estar avaladas por un buen control de ensayos. Por tanto, es lógico pensar que desplazamientos en el eje B de los inclinómetros deberían ser prácticamente cero. Recordemos que el eje B es la pantalla: es imposible que un tubo de aluminio, metido dentro de un tubo de PVC, relleno de mortero, y todo a su vez en una pantalla de hormigón con una longitud mínima de 60 metros, se desplace en el sentido donde está toda la inercia y rigidez de la pantalla.

Sin embargo, desplazamientos en el eje A de los inclinómetros en la lectura inicial, podría reflejar defectos de ejecución durante el proceso de excavación y posterior hormigonado del batache.

\section{CONCLUSIONES}

La construcción de pantallas profundas, debe llevar consigo la adopción de medidas adicionales de control: verticalidad de la excavación mediante instrumentación que nos dé un control instantáneo del proceso constructivo (diagrafías) y colocación de juntas entre bataches continuos (juntas trapezoidales con cintas de PVC waterstop). Estas medidas nos darán en unos casos información sobre que batache tratar posteriormente en caso de fallo o actuarán de manera preventiva impidiendo la entrada de agua al interior de la excavación en caso de fallo de la unión entre bataches.

Ante la aparición de problemas de filtración en las pantallas realizas para excavación de sótanos en edificaciones, detectadas durante el proceso de instrumentación del movimiento de las mismas o bien durante el proceso de excavación del interior del solar, se debe actuar realizando el sellado de las juntas mediante inyecciones de jet-grouting que deberán realizarse desde la superficie en el exterior del perímetro de las pantallas o bien desde el interior de la excavación siempre y cuando se actúe por debajo del nivel de discontinuidad.

Se recomienda que en zonas con presencia de restos arqueológicos o discontinuidades del perfil geotécnico y a profundidades de excavación superiores a $15 \mathrm{~m}$, utilizar el empleo de maquinaria con vigas guía o hidrofresa, ya que el procedimiento de excavación se fundamenta en una estructura pesada de acero provista en su parte inferior de dos ruedas de corte situadas en un plano vertical que garantiza la no desviación de los bataches a excavar.

\section{REFERENCIAS}

(1) CTE. Documento Básico Seguridad Estructural. CTE BD-SE Cimientos. Ministerio de fomento - Código Técnico de la Edificación.

(2) Jimenez-Salas, J.A. ( 1979). Geotecnia y Cimientos III. Madrid: Editorial Rueda.

(3) Oteo, C., Rodriguez-Ortiz, J. Melis, M. (2003). Criterios de diseño de pantallas contínuas en la ampliación del Metro de Madrid. Revista de Ingeniería Civil, 129: 5-15.

(4) De Justo-Alpañés, E., Rodriguez-Liñán, C., Jaramillo-Morilla, A. Programa de elementos finitos para el cálculo de pantallas con simulación del proceso constructivo. Universidad de Sevilla.

(5) Clough, G.W. (1990). Construction Induced Movements of in situ Walls. Design and Performance of Earth Retaining Structures, ASCE Geotechnical Special Publication, (pp. 439-470). New York.

(6) Bustamante, M. (1986). Un método para el cálculo de los anclajes y de los micropilotes inyectados. Boletín de la SEMSC, no 81-82. Madrid.

(7) Dirección General de Carreteras. (2001). Guía para el diseño y la ejecución de anclajes al terreno en obras de carretera. Madrid. 